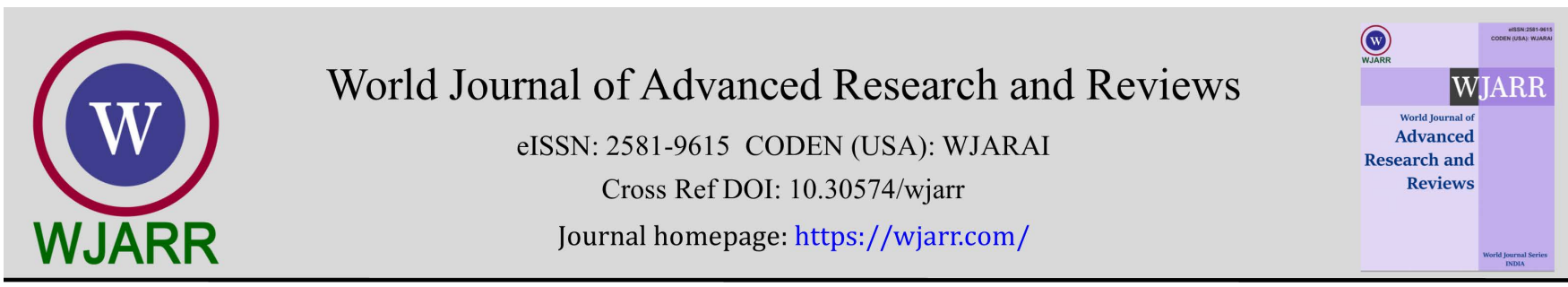

(REVIEW ARTICLE)

\title{
A Review on Potentilla fulgens (Wall. Ex Hook) and its pharmacological efficacy
}

\author{
Pradeep Kumar* \\ Department of Zoology, S.G.N. Govt. P.G. College, Muhammadabad Gohna, Mau, 276403, U.P. India.
}

World Journal of Advanced Research and Reviews, 2021, 10(03), 141-145

Publication history: Received on 03 May 2021; revised on 06 June 2021; accepted on 08 June 2021

Article DOI: https://doi.org/10.30574/wjarr.2021.10.3.0270

\begin{abstract}
Potentilla fulgens (Wall.) ex Hook (Rosaceae) is an alpine medicinal plant that is found in the Western Himalayas region and its whole parts are consumed all over the world as a potent source of therapeutic constituents. Traditionally this plant is frequently used by tribals and their various products are also uses by common peoples for caring for various diseases especially in pyorrhea. The various parts of $P$. fulgens and their different extracts have a variety of active phytochemicals such as polyphenol, triterpenoids, flavonoids, triterpenes, potentene-A (30-methyl-17 $\alpha$-hypan-12-ene3 one), Potentene-B (3-0- $\beta$-D-gluconopyranosyl-(1,2)- $\beta$-D-gluconopyranosyl hopan-12-eno-11-oxo-28oic acid, novel bioflavonoid potifulgene (Epiafzelchin-6-0-8" epiafzelchin), and epicatechin compound. Pharmacologically the whole parts of $P$. fulgens are uses in the control of various critical and infectious diseases. This review of literature revealed that $P$. fulgens can be used as a potent source of antioxidants, anthelmintic, anticancerous, antihyperglycemic or hypoglycemic, antitumor, and molluscicides. It also propagates an approach towards new researches that how the various phytochemical of $P$. fulgens act at the molecular level in the organisms.
\end{abstract}

Keywords: Potentilla fulgens; Antioxidants; Anthelmintic; Anticancerous; Antihyperglycemic; Molluscicides

\section{Introduction}

Potentilla is an important therapeutic medicinal plant that is commonly found at high altitudes of Himalayan range. More than three hundred species of the genus Potentilla are used in Unani, Ayurvedic, Chinese, and Tibetan system in the form of medicine [1-5]. Potentilla fulgens L (Family: Rosaceae) is an important local medicinal plant the root extract of this plant are widely used in caring several human diseases [6]. Potentilla fulgens is commonly called Bajradanti in Hindi, Himalayan Cinquefoil in English, [7], Bajradanti, Ganephus and Dentamanjan in Nepali [7, 8], and Lyngniangbru in Meghalaya [7]. This plant has several important phytochemical constituents such as polyphenols, triterpenoids, and flavonoids therapeutic and commercial importance [5]. Potentilla fulgens always grow in the natural habitat, but the first time it was cultivated outside its natural habitat at Palampur, Himanchal Pradesh, India [9]. The whole parts of $P$. fulgens and root-stock are utilized as astringent and tonic for caring for gum, and tooth ailments (Pyorrhea, toothache and caries), diarrhea, stomach problems, cough, cold, diabetes mellitus, and cancer disease [5]. Therefore, the present reviews were taken up to investigate several phytochemical constituents and pharmaceutical properties of the $P$. fulgens.

\section{Phytochemistry}

All groups of plants have specific phytochemicals which uses in caring for several diseases. The plant species Potentilla contain a high amount of tannins, and a lesser extent of polyphenol, triterpenoids, and flavonoids phytochemical constituents [10]. The various investigation of the aerial part of $P$. fulgens yield two new triterpenes, Potentene-A (30methyl-17 $\alpha$-hypan-12-ene-3 one) and Potentene-B (3-0- $\beta$-D-gluconopyranosyl- $(1,2)-\beta$-D-gluconopyranosyl hopan-

\footnotetext{
* Corresponding author: Pradeep Kumar

Department of Zoology, S.G.N. Govt. P.G. College, Muhammadabad Gohna,Mau, 276403, U.P. India.

Copyright (C) 2021 Author(s) retain the copyright of this article. This article is published under the terms of the Creative Commons Attribution Liscense 4.0.
} 
12-eno-11-oxo-28oic acid, along with three known compounds, such as afzelchin- $4 \alpha \rightarrow 8$ " catechin, epiafzelchin, and rutin [11].The investigation of the root part of $P$. fulgens led to the isolation of a novel bioflavonoid potifulgene (Epiafzelchin-6-0-8" epiafzelchin) along with epicatechin compound [12].

\section{Pharmacological properties}

The World Health Organization (WHO) has been reported that $80 \%$ of the world's population depends on plants for primary health care [13]. In the form of traditional medicine, the root extract of $P$. fulgens is uses for the treatment of bacterial disease diabetes, cancer, and parasitic infections $[14,15]$. The various studies has been confirmed that the traditional use of Potentilla and their aerial and underground part of the extract at therapeutically uses in several diseases due to high amounts of condensed, and hydrolysable tannine [10]. All parts of $P$. fulgens are used in various forms for the caring of tooth problems (pyorrhea), stomach problems (diarrhea), cold, cough, diabetes, and cancer [5, 16 , 17]. In Bhutan and Nepal, the juices of whole parts of $P$. fulgens are taken for the curing of respiratory complications like cough, cold, and stomach problems [5, 8]. The masticated leaves of $P$. fulgens are uses in the treatment of pyorrhea [8]. The leaf, stem, and root of the P. fulgens are frequently used for the treatment of stomatitis and aphthae in Uttarakhand, India [18]. At commercial levels, the whole plant of $P$. fulgens is utilized by Vicoo Laboratories in India for the production of Vicoo Vajradanti tooth powder and pest $[7,19]$. Therefore, any part of the P. fulgens can be used in pharmaceutics, in which some pharmaceutical activities are as follow.

\subsection{Antioxidant activity}

The components of antioxidants play an important role in the removal of toxic components from the vital system. These components are present in the various parts of the plant groups in the form of active phytochemical components. Their chemical constituents and amounts may be variable according to plant species. The medicinal plant Potentilla species are also having several antioxidant components in the aerial and ground parts [14,16, 17, 20-23]. The aqueous methanolic, ethyl acetate, butanol, and water extract of the $P$. fulgens root have antioxidant activity [11]. Syiem et al., [16] have been reported that in vitro system P. fulgens is wide uses in the form of antioxidant components. Jaitak et al., [11] have been reported that the antioxidant compounds epicatechin and biflavanoid (Potifulgene) are present in the various parts of the $P$. fulgens. The methanolic root extract of $P$. fulgens reduces free radical-mediated oxidative stress in diabetic mice [24]. This medicinal plant showed good antioxidant activity and it can be a potent and useful source of natural antioxidants [25].

\subsection{Anthelmintic activity}

Helminthiasis is one of the most important problems in the productivity of grazing livestock as well as the health of human beings throughout the world [26]. To control the helminthes infection, a variety of anthelmintic commercial are available; however, due to the increasing development of anthelmintic resistance in the host body, the limited availability of anthelmintic drugs for the rural people as well as the high cost of such synthetic anthelmintic medicines, a growing interest in the plant products to examine the various anthelmintic properties of which traditional used by the local peoples in different parts of the world's [27-29]. The traditionally uses of the medicinal plant $P$. fulgens are exhibited cestocidal and trematocidal infections [30-32].The ethanolic extracts of $P$. fulgens have potential anthelmintic activity against the cestode parasite [6]. The organic extract ether, chloroform, methanol, acetone, ethanol, and column purified fractions of root powder of the $P$. fulgens in vivo and in vitro have anthelmintic larvicidal activities against trematode larva (sporocyst, redia, and cercaria) of Fasciola gigantica [32, 33]. The aqueous root extract of the P. fulgens is uses in the treatment of intestinal parasitic infection [14]. The root powder of $P$. fulgens is an effective anthelmintic and is used for toothache and stomach disorders [5]. The root juice of this plant is taken for the treatment of disusia and peptic ulcers [8], whereas, root paste is used for controlling of tooth infections [34]. The leaves of $P$. fulgens, when masticated in the mouth are beneficial for the treatment of pyorrhea protozoon [8].

\subsection{Anticancerous activity}

The synthetic drugs are frequently used in the treatment of cancerous disease which has a side effect among surrounding cells and it also developing resistance. Therefore, the vision of the human drawn towards the uses of phytochemicals and trial it's as an alternative source of synthetic drugs. Phytochemicals may be an important source for the treatment of cancerous disease. The methanolic, butanolic, and dichloromethane root extracts of $P$. fulgens in vitro have cytotoxic activity against various human cancer cell lines such as liver, ovary, lung, prostate, neuroblastoma, and leukemia [35]. The methanolic root extract of $P$. fulgens was found to increase the in vivo survival of mice bearing Ehrlich ascites cells and also showed a dose-dependent inhibitory effect on the growth of MCF-7 cells through clonogenic assay [36]. The root of $P$. fulgens is used in the treatment of various ailments, including neoplastic disease 
[15]. The aqueous root extract of $P$. fulgens is active against neoplastic tumours murine ascites Dalton's lymphoma, depending on the method of administration [37].

\subsection{Antihyperglycemic or Hypoglycemic}

The developing countries are the focus on the utilization of natural gradients for caring for various diseases. Previously the native plant species are frequently used by common peoples for the treatment of critical diseases. The medicinal plant $P$. fulgens was found successful in reducing the serum cholesterol (72\%) triglyceride levels (80\%) and improved HDL cholesterol to normal level using inter peritoneal mode [17].The roots of $P$. fulgens have hypoglycemic and antihyperglycemic properties in the mice [14]. The methanolic root extract of $P$. fulgens has hypoglycemic and antihyperglycemic activities in normal and allaxan-induced diabetic mice [14]. It's also has effect on lipid profiles in alloxan-induced diabetic mice [17]. Syiem and Majaw [38] have been studies that the methanolic extract of the P. fulgens is inhibiting sorbital dehydrogenase, the second enzyme in the polyol pathway, responsible for the conversion of sorbitol to fructose.

\subsection{Antitumor activity}

In animals, the growth of the tumor is very harmful which produces by the infection of various microorganisms, cellular coordination and various organic/inorganic components in the body. Various researches have been reported that plantderived phytochemicals are a potent source as an antitumor in various animals [39]. Therefore, the growth of the tumors can be control by the use of plant products. The whole plant of the P. fulgens is active against the neoplastic tumours murine ascites Dalton's lymphoma [15]. The methanolic root extract of the $P$. fulgens has potent dose-dependent antitumor activity on Dalton's lymphoma cells [37]. Laloo et al., [40] have been reported that ethanolic root extract of $P$. fulgens is significantly inhibits pyloric ligation-induced gastric ulcers due to its anti-secretary properties.

\subsection{Molluscicidal activity}

The species of snail and slugs are harmful to domestic animals and livestock keepers as a carrier of trematode parasites and destruction of agricultural fields [41]. Synthetic chemicals frequently can be used for the control of snails and slugs but these chemicals cause an adverse impact on the other aquatic and terrestrial organisms. The phytochemicals are important and suitable as natural products which can be used as molluscicides without any adverse impact on the ecosystem and non-target organisms. The organic root extract (ether, chloroform, methanol, acetone, and ethanol) of $P$. fulgens have potent molluscicidal components and it can be used as effective molluscicides in the control of intermediate host snails Lymnaea acuminata and Indoplanorbis exustus [42-44].

\section{Conclusion}

The various pharmacological studies of medicinal plant $P$. fulgens conform that the whole part of this plant have specialized phytochemical constituents which have a specific characteristic and it can be used as products of antioxidants, anthelmintic, anticancerous, antihyperglycemic or hypoglycemic and antitumor in the traditional to modern therapeutics. The various organic root extract of $P$. fulgens are the potent source which has potent molluscicidal components and it can use for the control of harmful snails. The review of literature revealed the further need for various studies that the products of $P$. fulgens how to perform the mode of action at the molecular level in the vital systems at various steps and action in the therapeutics of various diseases and effective against organisms.

\section{Compliance with ethical standards}

\section{Acknowledgments}

The author is thankful to S.G.N. Govt. P.G. College Muhammadabad Gohna, Mau, India for providing necessary facilities.

\section{References}

[1] Delgado L, Gallego F, Rico E, Karyosystematic study of Potentilla L. subgenus Potentilla (Rosaceae) in the Iberian Peninsula. Bot. J. Linn. Soc. 2000; 132(3): 263-280.

[2] Xue PF, Luo G, Zeng WZ, Zhao YY, Liang H. Secondary metabolites from Potentilla multifida Linn. (Rosaceae). Biochem. Syst. Ecol. 2005; 33(7): 725-728. 
[3] Xue PF, Zhao YY, Wang B, Liang H. Secondary metabolites from Potentilla discolor Bunge (Rosaceae). Biochem. Syst. Ecol. 2006; 34(11): 825-828.

[4] Zhao YL, Cai GM, Hong X, Shan LM, Xiao XH. Anti-hepatitis B virus activities of triterpenoid saponin compound from Potentilla anseria L. Phytomedicine. 2008; 15(4): 253-258.

[5] Kaul K, Jaitak V, Kaul VK. Review on pharmaceutical properties and conservation measures of Potentilla fulgens Wall. Ex Hook. A medicinal endangered herb of higher Himalaya. Indian J. Nat. Prod. Resour. 2011; 2: 298-306.

[6] Roy B, Swargiary A, Syiem D, Tandon V. Potentilla fulgens (Family Rosaceae), a medicinal plant of North-East India: a natural anthelmintic. J. Parasitic Dis. 2010; 34: 83-88.

[7] Panigrahi G, Dixit BK. Studies on taxonomy and economic utilization of twelve species of Potentilla (Rosaceae) in India. J. Econ. Rax. Bot. 1980; 1(1-2): 127.

[8] Manandhar NP, Manandhar S. Plants and people of Nepal (ed. Timber Press, Oregon, USA). $2002 ; 377$.

[9] Kaul K, Ex-situ conservation of Potentilla fulgens- A threatened, alpine medicinal herb from western Himalaya. J. Med. Arom. Pl. Sci. 2008; 30(4): 43-48.

[10] Tomczyk M, Latte KP. Potentilla- A review of its phytochemical and pharmacological profile. J. Ethnopharmacol. 2009; 122(2); 184-204.

[11] Jaitak V, Kaul VK, Himlata, Kumar N, Singh B, Dhar J, Sharma OP. New hopanetriterpenes and antioxidant constituents from Potentilla fulgens. Natural Products Communications. 2010; 5: 1561-1566.

[12] Jaitak V, Sharma K, Kalia K, Kumar N, Singh HP, Kaul VK, Singh B. Antioxidant activity ofPotentillafulgens: an alpine plant of Western Himalaya. Journal of Food Composition and Analysis. 2010; 23: 142-147.

[13] Farnsworth NR, Akerele 0, Bingen AS, Soejarto DD, Zhengang G. Medicinal plants in therapy, Bulletin World Health Organisation.1985; 63: 965-981.

[14] Syiem D, Syngai G, Khup PZ, Khongwir BS, Kharbuli B, Kayang H. Hypoglycemic effects of Potentilla fulgens L. in normal and alloxan-induced diabetic mice. J. Ethnopharmacol. 2002; 83; 55-61.

[15] Rosangkima G, Prasad SB. Antitumour activity of some plants from Meghalaya and Mizoram against murine ascites Dalton's lymphoma. Indian J. Exp. Biol. 2004; 42: 981-988.

[16] Syiem D, Sharma R, Saio V. In vitro study of the antioxidant potential of some traditionally used medicinal plants of North-East India and assessment of their total phenolic content. Pharmacologyonline. 2009; 3: 952-965.

[17] Syiem D, Khup PZ, Syiem AB. Effects of Potentilla fulgens Linn on carbohydrate and lipid profiles in diabetic mice. Pharmacologyonline. 2009; 2: 787-795.

[18] Pala NA, Negi AK, Todaria NP. Traditional uses of medicinal plants of Pauri Garhwal, Uttrakhand. New York Sci. J. 2010; 3(6): 61-65.

[19] Farooqui AHA, Jain SP, Shukla YN, Ansari SR, Kumar S. Medicinal plants in oral health care in India. J. Med. Arom. Pl. Sci. 1998; 20(2): 441.

[20] Chai YH, Kim MJ, Lee HS, Yum BS, Hu C, Kwak SS. Antioxidative compounds in aerial parts of Potentilla fragarioides. Korean J. Pharmacogn. 1998; 29: 79-85.

[21] Leporatti M, Ivancheva S. Preliminary comparative analysis of medicinal plants used in the traditional medicine of Bulgaria and Italy. J. Ethnopharmacol. 3003; 87(2-3): 123-142.

[22] Miliauskas G, Vanbeek TA, Venskutonis PR, Linssen JPH, Waard PD, Sudholter EJR. Antioxidant activity of Potentilla fulgens. J. Sci. Food Agric. 2004; 84(15): 1997-2009.

[23] Gurbuz I, Ozkan AM, Yesilada E, Kutsal O. Anti-ulcerogenic activity of some plants used in folk medicine of Pinarbasi (Kayseri, Turkey). J. Ethanopharmacol. 2005; 101(1-3): 313-318.

[24] Saio V, Syiem D, Sharma R. Effect of Potentilla fulgens on lipid peroxidation and antioxidant status in alloxaninduced diabetic mice. Journal of Basic and Clinical Pharmacy. 2012; 3(2): 249-254.

[25] Choudhary A, Mittal AK, Radhika M, Tripathy D, Chatterjee A, Banerjee UC, Singh IP. Two new stereoisomeric antioxidant triterpens from Potentilla fulgens. Fitoterapia. 2013; 91: 290-297.

[26] WHO. Traditional medicine strategy 2002-2005; WHO/EDM/TRM/2002. 2002; 1: 61. 
[27] Kaplan RM. Drug resistance in nematodes of veterinary importance: a status report. Trends Parasitol. 2004; 20: 477-481.

[28] Jegede OC, Ikani IE, Dafwany II, Bolorunduro PI, Annatte AI. Traditional animal healthcare practices in disease prevention and control by snail ruminant farmers in Oyostate, Nigeria. J. Food Agr. Environ. 2007; 5: 163-164.

[29] Mali RG, Mehta AA. A review on anthelmintic plants. Nat. Prod. Rad. 2008; 7: 466-475.

[30] Roy B, Tandon V. Effect of root-tuber extract of Flemingia vestita, a leguminous plant, on Artyfechinostomum sufrartyfex and Fasciolopsis buski: a scanning electron microscopy study. Parasitol Res.1996; 82: 248-252.

[31] Tandon V, Pal P, Roy B, Rao HSP, Reddy KS. In vitro anthelmintic activity of root-tuber extract of Flemingia vestita, an indigenous plant in Shillong, India. Parasitol Res. 1997; 83: 492-498.

[32] Kumar P, Sunita K, Singh RN, Singh DK. Fasciola larva: Anthelmintic activity of medicinal plant Potentilla fulgens against sporocyst, redia and cercaria. Asian Journal of Advances in Research. 2020; 3(3): 24-30.

[33] Kumar P. Medicinal plant Potentilla fulgens and its effect in vitro against Fasciola gigantica. Insights in Clinical and Cellular Immunology. 2021; 5: 004-007.

[34] Maikhuri RK, Nautiyal S, Rao KS, Saxena KG. Role of medicinal plants in the traditional health care system: A case study from Nanda Devi Biosphere Reserve. Curr. Sci. 1998; 75(2): 152-157.

[35] Bora M, Baruah D, Upadhyay SN, Lalrinpuia, Hazra J. Anticancer potential of some Ayurvedic plants of North Eastern India: A comprehensive Pharmacological Review. Int. J. Res. Ayurveda Pharm. 2017; 8(2): 4-8.

[36] Radhika M, Ghoshal N, Chatterjee A. Comparison of effectiveness in antitumor activity between flavonoids and polyphenols of the methanolic extract of roots of Potentilla fulgens in brest cancer cells. J. Complement Integr. Med. 2012; 9: 1644.

[37] Syiem D, Syngkai C, Kharbuli B, Kayang H, Khongwir BS. Anti-tumor activity of crude root extract of Potentilla fulgens. Indian Drugs. 2003; 40: 124-125.

[38] Syiem D, Majaw S. Effect of Potentilla fulgens L. methanolic extract on sorbitol dehydrogenase in normal and alloxan-induced diabetic mice. Pharmacologyonline. 2010; 2: 671-680.

[39] Khan T, Ali M, Khan A, Nisar P, Jan SA, Afridi S, Shinwan ZK. Anticancer plants: A review of the active phytochemicals, Application in animal models, and Regulatory Aspects. Biomolecules. 2020; 10(47): 1-30.

[40] Laloo D, Prasad SK, Krishnamurthy S, Hemalatha S. Gastroprotective activity of ethanolic root extract of Potentilla fulgens Wall. Ex Hook. Journal of Ethnopharmacology. 2013; 146: 505-514.

[41] Kumar P. A review-On Molluscs as an Agricultural pest and their control. International Journal of Food Science and Agriculture. 2021; 4(4); 383-389.

[42] Kumar P, Sunita K, Singh DK. Efficacy of Potentilla fulgens root powder and their different organic extract against fresh water vector snail Lymnaea acuminata. Asian Journal of Animal and Veterinary Advances. 2017; 13: 30-34.

[43] Kumar P, Sunita K, Singh DK. Molluscicidal activity of different organic root extract of Potentilla fulgens against liver fluke vector snail Indoplanorbis exustus. Asian Journal of Animal Science. 2018; 12(1): 30-35.

[44] Kumar P. Effect of medicinal plant Potentilla fulgens against fecundity, hatchability and survival of Fasciola host snail Indoplanorbis exustus. Indian Journal of Scientific Research. 2021; 11(2): 19-24. 